J Am Med Dir Assoc. 2014 April ; 15(4): 251-255. doi:10.1016/j.jamda.2013.11.020.

\title{
Development and Testing of a Decision Aid on Goals of Care for Advanced Dementia
}

\author{
Seth F. Einterz ${ }^{1,2}$, Robin Gilliam, MSW ${ }^{1}$, Feng Chang Lin, $\mathrm{PhD}^{3}$, J. Marvin McBride, MD ${ }^{4}$, \\ and Laura C. Hanson, MD, MPH ${ }^{1,4,5}$ \\ ${ }^{1}$ Cecil G. Sheps Center for Health Services Research, University of North Carolina, Chapel Hill, \\ $\mathrm{NC}$ \\ ${ }^{2}$ Georgetown University School of Medicine, Washington, DC \\ ${ }^{3}$ Department of Biostatistics, School of Public Health, University of North Carolina, Chapel Hill, \\ NC \\ ${ }^{4}$ Division of Geriatric Medicine and Center for Aging and Health, University of North Carolina, \\ Chapel Hill, NC \\ ${ }^{5}$ Palliative Care Program, University of North Carolina, Chapel Hill, NC
}

\begin{abstract}
Objectives-Decision aids are effective to improve decision-making, yet they are rarely tested in nursing homes (NHs). Study objectives were to 1) examine the feasibility of a Goals of Care (GOC) decision aid for surrogate decision-makers (SDMs)of persons with dementia; and 2) test its effect on quality of communication and decision-making.
\end{abstract}

Design-Pre-post intervention to test a GOC decision aid intervention for SDMs for persons with dementia in NHs. Investigators collected data from reviews of resident health records and interviews with SDMs at baseline and 3-month follow up.

Setting-Two NHs in North Carolina.

Participants -18 residents who were over 65 years of age, had moderate to severe dementia on the Global Deterioration Scale (GDS=5,6,7), and an English-speaking surrogate decision-maker.

Intervention-1) GOC Decision Aid video viewed by the SDM, and 2) a structured care plan meeting between the SDM and interdisciplinary $\mathrm{NH}$ team

Measurements-Surrogate knowledge, quality of communication with health care providers, surrogate-provider concordance on goals of care, and palliative care domains addressed in the care plan.

Results-89\% of the SDMs thought the decision aid was relevant to their needs. After viewing the video decision aid, SDMs increased the number of correct responses on knowledge-based questions (12.5 vs 14.2, $\mathrm{P}<.001)$. At 3 months they reported improved quality of communication scores (6.1 vs $6.8, \mathrm{P}=.01)$ and improved concordance on primary goal of care with nursing home

(C) 2013 American Medical Directors Association. Published by Elsevier Inc. All rights reserved. CONFLICT OF INTEREST: Authors have no associated conflicts of interest to report.

Publisher's Disclaimer: This is a PDF file of an unedited manuscript that has been accepted for publication. As a service to our customers we are providing this early version of the manuscript. The manuscript will undergo copyediting, typesetting, and review of the resulting proof before it is published in its final citable form. Please note that during the production process errors may be discovered which could affect the content, and all legal disclaimers that apply to the journal pertain. 
team $(50 \%$ vs $78 \%, \mathrm{P}=.003)$. The number of palliative care domains addressed in the care plan increased (1.8 vs $4.3, \mathrm{P}<.001)$.

Conclusion-The decision-support intervention piloted in this study was feasible and relevant for surrogate decision-makers of persons with advanced dementia in nursing homes, and it improved quality of communication between SDM and NH providers. A larger randomized clinical trial is underway to provide further evidence of the effects of this decision aid intervention.

\section{Keywords}

dementia; goals of care; decision-making

\section{INTRODUCTION}

More than 5 million Americans have dementia, and 1 million have advanced dementia. ${ }^{1-3}$ The 6-month mortality risk of advanced dementia is $28 \%$ and median survival is 1.3 years. ${ }^{4-6}$ Complications such as dysphagia or infection most often precede death. ${ }^{6-9}$ In the United States, $67 \%$ of dementia-related deaths occur in nursing homes. ${ }^{10}$ Nursing home staff excel in many aspects of dementia care, but research raises concerns about the quality of palliative care. In a nationwide after-death survey, surviving family express more dissatisfaction with nursing homes than other sites of care. ${ }^{11}$ Poor quality communication is a barrier to making difficult choices about care for their loved ones with advanced dementia, including resuscitation, hospital transfer, feeding options and treatment of infection. ${ }^{12-14}$ In the prospective CASCADE Study (Choices, Attitudes and Strategies for Care of Advanced Dementia), only $38 \%$ of surrogate decision-makers recalled involvement in medical decisions, and less discussion time was associated with greater dissatisfaction with end-oflife care. ${ }^{15,16}$

Decision aids provide video or print information to help decision-makers consider how risk, uncertainty, and values may affect a clinical choice. ${ }^{17}$ Decision aids are effective to improve the quality of decision-making, yet they have rarely been tested in nursing homes. ${ }^{18-25}$ Only two decision aids addressing dementia have been rigorously tested - one addressing advance care plans for dementia among cognitively intact patients, and one focused on feeding options for advanced dementia. 26,27 .

Goals of care decisions focus on the choice of medical care to prolong life, maintain function, or promote comfort as primary goals. ${ }^{28-31}$ Using a pre-post study design, we tested a decision aid on goals of care for surrogates making choices for nursing home residents with advanced dementia. Study objectives were 1) to examine the feasibility and relevance of the Goals of Care decision aid intervention; and 2) to test initial effects on quality of communication and surrogate decision-making.

\section{METHODS}

\section{Design overview}

This was a pilot study with a 3 month pre-post intervention design. (Figure 1) The intervention consisted of two components: 1) a Goals of Care video decision aid viewed by the surrogate decision-maker, and 2) an in-person structured care plan meeting between the surrogate decision-maker and the interdisciplinary nursing home team. The study was conducted between May 2011 and April 2012. All study procedures were reviewed and approved by the University of North Carolina Institutional Review Board for research with human subjects. 


\section{Subjects and recruitment}

Study sites were two nursing homes; one for-profit free-standing facility and one not-forprofit facility within a larger retirement community. Residents were eligible if they had a diagnosis of dementia, and severity was moderate to advanced based on the Global Deterioration Scale (GDS) staging of 5, 6, or 7 rated by their primary nurse. ${ }^{4}$ Surrogates were eligible to participate if they were the patient's health care agent by virtue of an executed health care power of attorney or NC surrogacy law, and spoke English. Surrogates provided written informed consent for their participation and for review of medical records.

\section{Development of the video decision aid}

The Goals of Care video decision aid was developed systematically by the investigators, with reference to International Patient Decision Aid Standards. ${ }^{17}$ Content includes information about advanced dementia, role of the surrogate decision-maker, treatment goals, and treatment options consistent with each goal. Provided in video and print formats, it uses patient stories, balanced presentation, and simple language to enable comprehension at an $8^{\text {th }}$ grade educational level. The draft decision aid was reviewed for clarity and bias in cognitive interviews with 12 surrogates, $50 \%$ of whom were African-American; it was refined based on their feedback.

\section{Decision aid intervention}

The decision aid intervention consisted of two parts: 1) an 18-minute Goals of Care video decision aid, and 2) a structured meeting between the surrogate and the interdisciplinary care plan team at the nursing home within the next 3 months (Figure 1). Decision aid content covered central elements of shared decision-making based on Braddock's framework, ${ }^{32}$ including a) the surrogate's role, b) prognosis and goals of care for medical treatment of advanced dementia, c) treatment approaches to meet the primary goals of longevity, function or comfort, d) consideration of personal goals and values, and e) the pros and cons of each choice for a primary goal and related treatments. An example of still shots to illustrate decision aid content is provided in Figure 1. The decision aid encouraged further discussion with healthcare providers, and included a printed guide to assist in this discussion. The printed guide contained identical content to the video decision aid, augmented by a short set of definitions of medical terminology and questions to prompt discussions with healthcare providers.

A standard care plan meeting was re-structured to permit the surrogate and the nursing home interdisciplinary team to consider goals of care. Investigators instructed and encouraged the nursing home care plan staff to utilize the "VALUE" framework (Value family comments, Address emotions, Listen, Understand the patient as a person, and Elicit family questions) to discuss goals of care. ${ }^{33}$ Staff viewed the video and received a copy of the printed information given to surrogates.

\section{Measures}

Data collection consisted of surrogate interviews and resident chart reviews at baseline and at 3- month follow-up. Baseline interviews lasted 90 minutes and were conducted in-person when possible unless the surrogate lived out of the area. All follow-up interviews were conducted over the phone, and lasted about 45 minutes.

To establish feasibility and relevance of the decision aid intervention, investigators collected data on fidelity to the intervention, and surrogates' perception of its relevance. Fidelity was defined as percent adherence to each of the following items at the care plan meeting: 1) presence of the surrogate decision-maker, 2) presence of primary health care provider, 3) 
discussion of goals of care, 4) selection of primary goal, and 5) formation of treatment plan. Open-ended questions during interviews with surrogates were used to assess the perceived relevance, ease of use, and helpfulness of the intervention.

To understand the effect of the decision aid intervention on quality of communication, main outcomes were a) surrogate knowledge, b) quality of communication, c) surrogate-provider concordance, and d) number of palliative care domains addressed in the care plan. Surrogate knowledge was assessed during the baseline interview with 18 true/false items regarding dementia, goals of care, and treatment options. These items were asked before and after viewing the decision aid in the baseline interview. Quality of communication with nursing home providers was measured at baseline and 3-month follow-up interviews using the Quality of Communication (QOC) instrument. ${ }^{34,35}$ The QOC consists of 13 items rated on a 10-point scale; items form two subscales measuring general (Cronbach's alpha=0.91) and end-of-life communication (Cronbach's alpha $=0.79$ ). Surrogate-provider concordance on Goals of Care was defined as the percent of family surrogates who report that their primary goal and the primary goal of the nursing home staff are the same. Surrogates were first asked to choose what the resident would say is the most realistic goal of care as a measure of their primary goal. Next, surrogates were asked "Based on your discussions with the nursing home providers, what you believe is the current goal used to guide [resident's] treatment now?" This item was used to define the nursing home team's goal, and was asked during interviews at baseline and at 3-month follow-up.

The number of palliative care domains addressed in care plans was measured in baseline and follow-up chart reviews. Investigators sought care information on 10 domains of palliative care. Each domain was scored as present or absent, for a potential score from 0-10. Included domains were prognosis, goals of care, plan to assess and treat physical symptoms, plan to assess and meet emotional needs, plan to assess and meet spiritual needs, and preferences for use of 5 treatments: resuscitation, artificial feeding, antibiotics, hospital transfer and hospice. An outcome was scored if the aspect of care was addressed in the chart reviews, and scoring was not dependent on particular choices for or against treatment.

\section{Secondary Outcome Measures}

Secondary outcomes included the frequency of communication regarding goals of care, satisfaction with care, resident quality-of-life, and symptom management. Frequency of communication was measured at baseline and follow-up interview by asking the surrogate if they had discussed goals of care with a) the resident's nursing home physician, b) with a nurse practitioner or physician's assistant in the nursing home, and c) with any member of the nursing home interdisciplinary team. Satisfaction with care was measured using the Satisfaction with Care at the End of Life in Dementia (SWC-EOLD) instrument (Cronbach's alpha $0.83-0.90$ ). Scores range from 10-40, with higher scores indicating better satisfaction. The Quality of Life in Late-Stage Dementia (QUALID) scale is a surrogate measure of quality of life specifically developed for advanced dementia patients (Cronbach's alpha $=$ 0.77). Surrogates were asked to rate 11 activities and emotional states on a 5- point Likert scale during a 1 week look-back period; scores range from 12-45 and higher scores indicate a worse quality of life. Symptom management was measured with the Symptom Management at the End of Life in Dementia (SM-EOLD) instrument (Cronbach's alpha $0.68-0.78$ ), which was developed and validated concurrently with the SWC-EOLD. This instrument asks surrogates to provide 1-month recall of symptom control for 6 psychological and 3 physical symptoms common in advanced dementia. The range of scores is $0-45$, with higher scores indicating better control of symptoms. 


\section{Statistical Analysis}

Analysis of feasibility and relevance relied on descriptive statistics to evaluate the percent adherence to elements of the intervention, and decision-maker responses in follow-up. Analysis of pre-to-post intervention differences in knowledge, quality of communication, concordance on primary goal, and number of palliative care domains used paired difference tests such as t-tests and McNemar tests when appropriate. Concordance on goals of care was analyzed as the percentage change of concordance rates between pre-intervention and 3 month via a McNemar test. P-values smaller than 0.05 were considered significant. All procedures were performed by IBM SPSS Statistics 21 (SPSS Inc., Chicago IL).

\section{RESULTS}

\section{Characteristics of the Study Subjects}

Out of 47 nursing home residents with dementia referred, 36 were eligible for the study, and 32 had surrogate decision makers available for contact. Eighteen contactable surrogates (56\%) agreed to participate. Decision makers who did not want to participate reported being too busy or uninterested, and some expressed concern they could not attend the care plan meeting. The mean age of residents with dementia was 90 years, and $83 \%$ were women (Table 1). The mean age of surrogates was 67 years. Most surrogates were female (56\%), and all of them were white. The surrogates were often children of the resident with dementia $(66 \%)$, most had an advanced degree (56\%) or college education (33\%), and reported their religion was Protestant $(67 \%)$. Surrogates visited the resident in the nursing home a mean frequency of 2.7 days in the week prior to enrollment.

\section{Fidelity to the Intervention}

Out of the 18 surrogate decision-makers in the study, all attended the baseline interview and watched the decision aid. Sixteen surrogates $(89 \%)$ attended the care plan meeting, while 2 did not (Table 2). At the 3 month follow up twelve of the original 18 surrogates (67\%) recalled that goals of care were discussed at the care plan meeting, and $11(61 \%)$ reported choosing a primary goal of care in shared decision-making with the nursing home care team. During most of the 18 care plan meetings the surrogate recalled they were asked for input regarding treatment (78\%), but less than half of the care plan teams (44\%) asked the surrogate about personal goals of the resident.

The primary healthcare provider - the attending physician or nurse practitioner or physician assistant - was present at only $2(11 \%)$ of the 18 care plan meetings. Following the meeting, documentation in the medical record only partially reflected this decision-making process: a Goals of Care discussion was documented in $6(33 \%)$ of the charts, a change in major treatment decisions was documented in 7 (39\%) of the charts, and a new goal of care was documented in 3 charts (17\%).

\section{Relevance of the Intervention}

Ten (56\%) of the surrogates thought the decision aid was relevant to a great extent, and 6 (33\% thought it was somewhat relevant. Of the eighteen surrogates, 16 (89\%) thought the decision aid was not difficult at all to use. Eleven of eighteen surrogates $(61 \%)$ thought the care plan meeting was helpful, while 3 surrogates (17\%) said that the meeting reviewed information they already knew. Assessing the intervention overall, most of the surrogates $(83 \%)$ thought the decision aid was useful or somewhat useful in the care plan meeting; the remaining surrogates were either unsure or did not attend the care plan meeting. The only negative comments were directed at the perceived redundancy of the intervention, as some surrogates expressed that they already understood everything revealed in the decision aid 
and the care plan meeting. Positive responses included comments the intervention improved clarity, confidence, and certainty.

\section{Effect on Quality of Communication and Decision-Making}

After reviewing the decision aid, surrogates improved their number of correct responses on knowledge-based questions (12.5 vs 14.2, $\mathrm{P}<.001)$ (Table 3$)$. At 3 months, surrogates reported a small but significant increase in the quality of communication $(6.1$ vs $6.8, \mathrm{P}=$. $011)$; in particular, the surrogates reported a significant increase on the subscale measuring Quality of Communication at End-of-Life (3.3 vs 4.7, P=.006). At baseline 67\% of surrogates chose comfort as the most realistic primary goal of care; after 3 months $78 \%$ chose comfort as the primary goal. After the intervention, surrogates reported an increase in surrogate-health care provider concordance on primary goal of care $(50 \%$ vs $78 \%, \mathrm{P}=.003)$. The mean number of palliative care domains addressed in the care plan also increased significantly after the intervention (1.8 vs $4.3, \mathrm{P}<.001)$.

\section{Secondary Outcomes}

At the 3 month follow-up interview, there was a significant increase in the percent of surrogates who reported that they had discussed goals of care with the nursing home nurse practitioner or physician's assistant (11\% vs $72 \%, \mathrm{P}=.001)$, with a nursing home physician ( $11 \%$ vs $44 \%, \mathrm{P}=.031)$ or with any other nursing home staff member ( $61 \%$ vs $94 \%, \mathrm{P}=.031)$. Surrogates also showed a trend indicating that more of them were "very involved" with decision making about goals of care after the intervention (56\% vs $83 \%, \mathrm{P}=.125)$. There was no significant change in surrogate satisfaction with care $(\mathrm{p}=.58)$. On the SM-EOLD, symptom management scores increased significantly ( $8.8 \mathrm{vs} 14.7, \mathrm{p}=.013)$, indicating somewhat improved control of symptoms over the three-month follow-up period, while quality of life for the resident with dementia did not change $(\mathrm{P}=.12)$.

\section{DISCUSSION}

This pilot study found that decision aid intervention addressing goals of care in advanced dementia is feasible, relevant to family surrogates, and shows promise for improving the quality of decision-making in nursing homes. Goals of care discussions are a fundamental component of shared decision-making. ${ }^{28,36}$ Gillick showed that nursing home residents or families of residents with dementia were willing to prioritize goals, and that clinicians were able to match possible treatments to a patient's ranking of the goals of care. ${ }^{30,37}$ The intervention piloted in this study facilitates the conditions for choosing and communicating a goal of care in nursing home care for persons with dementia. The intervention is purposefully designed to fit current nursing home practice standards, by providing video for short self-education of family caregivers followed by modest modification of the existing care plan meeting process.

Few interventions have addressed decision-making needed in dementia care. Arcand has designed an informational booklet for family caregivers which details major treatment decisions in advanced dementia. While not designed as a decision aid, its content encourages families to choose palliative options. The booklet was endorsed by nurses in long-term care settings; it has not been tested for its impact on family decision-makers. ${ }^{38}$ _Volandes has tested multiple video decision aids to assist cognitively intact elderly patients to define their advance care plans concerning many disease states and potential treatments, including advanced dementia. ${ }^{26,39,40}$ Compared to a verbal narrative alone, a video showing a patient with a disease (i.e. dementia) or specific treatments (i.e. a simulated code) increases the selection of comfort care options, narrows cultural and ethnic differences in decisionmaking, and increases concordance between cognitively-intact patients and their 
surrogates. ${ }^{41}$ Hanson has tested the only video decision aid directed at surrogate decisionmakers for patients with advanced dementia; the focus of the decision-aid was feeding options. ${ }^{27}$ Compared to usual care, surrogates who viewed the decision aid had improved knowledge and less decisional conflict, and they communicated more frequently with health providers. Patients in the intervention group had somewhat increased use of assisted feeding and less weight loss.

Nursing home health providers have limited time and training to assist with decisionmaking, and physicians rarely have direct contact with families in this setting, resulting in dissatisfaction with decision-making. ${ }^{12-14}$ With prompting to ensure clinical discussion, this decision aid intervention increased the frequency as well as the quality of communication between surrogates and health care providers, including physicians. Improving communication is a first step toward improving quality of care. However, in this study, family surrogates' satisfaction with care did not change, and their ratings of symptom management were somewhat improved. These findings may reflect the progressive nature of a disease such as dementia, or may also reflect the greater knowledge of the surrogates and their increased awareness of symptoms. Satisfaction has previously been inversely correlated with increased knowledge if this reflects an increased awareness of a terminal disease. ${ }^{42}$

This study has important limitations consistent with the pilot phase of research. Only 56\% of eligible surrogates participated, and while this response rate is typical for studies of seriously ill populations results may be affected by non-response bias. Surrogates respond favorably to the additional attention as a result of participation. Foremost, the design was a pre-post trial with a small and homogenous population. All residents and surrogates were white, and most surrogates were highly educated and visited the nursing home frequently. Future research must extend the intervention to a more representative population. The prepost nature of the study limits ability to discriminate effects of the intervention from effects of time on the decision-makers' experience and understanding. Future research with concurrent randomized attention controls is needed to overcome this limitation, and a trial of this type is in process.

\section{CONCLUSION}

The Goals of Care decision-support intervention was feasible and relevant, and improved both communication and quality of decision-making for advanced dementia care. Further testing of the intervention in a randomized controlled trial with sufficient sample size is required to establish effectiveness. Longer term follow-up may also be needed to understand the effects of decision support on actual treatment choices made for persons with advanced dementia.

\section{Acknowledgments}

Funding source: UNC-CH Summer Research in Aging for Medical Students, NIA 5-T35-AG038047-04; National Palliative Care Research Center; National Institute on Aging R01 AG037483

\section{References}

1. Hebert LE, Weuve J, Scherr PA, Evans DA. Alzheimer disease in the united states (2010-2050) estimated using the 2010 census. Neurology. 2013; 80(19):1778-1783. [PubMed: 23390181]

2. Todd S, Barr S, Roberts M, Passmore AP. Survival in dementia and predictors of mortality: A review. Int J Geriatr Psychiatry. 2013:n/a-n/a.10.1002/gps.3946 
3. Boustani M, Peterson B, Hanson L, Harris R, Lohr KN. Screening for dementia in primary care: A summary of the evidence for the US preventive services task force. Ann Intern Med. 2003; 138(11): 927-937. [PubMed: 12779304]

4. Reisberg B, Ferris SH, de Leon MJ, Crook T. The global deterioration scale for assessment of primary degenerative dementia. Am J Psychiatry. 1982; 139(9):1136-1139. [PubMed: 7114305]

5. Mitchell SL, Kiely DK, Hamel MB, Park PS, Morris JN, Fries BE. Estimating prognosis for nursing home residents with advanced dementia. JAMA. 2004; 291(22):2734-2740. [PubMed: 15187055]

6. Mitchell SL, Teno JM, Kiely DK, et al. The clinical course of advanced dementia. N Engl J Med. 2009; 361(16):1529-1538. [PubMed: 19828530]

7. Morrison RS, Siu AL. Survival in end-stage dementia following acute illness. JAMA: the journal of the American Medical Association. 2000; 284(1):47-52. [PubMed: 10872012]

8. Luchins DJ, Hanrahan P, Murphy K. Criteria for enrolling dementia patients in hospice. J Am Geriatr Soc. 1997; 45(9):1054-1059. [PubMed: 9288011]

9. Brandt HE, Deliens L, Ooms ME, van der Steen, Jenny T, van der Wal G, Ribbe MW. Symptoms, signs, problems, and diseases of terminally ill nursing home patients: A nationwide observational study in the netherlands. Arch Intern Med. 2005; 165(3):314. [PubMed: 15710795]

10. Mitchell SL, Teno JM, Miller SC, Mor V. A national study of the location of death for older persons with dementia. J Am Geriatr Soc. 2005; 53(2):299-305. [PubMed: 15673356]

11. Teno JM, Clarridge BR, Casey V, et al. Family perspectives on end-of-life care at the last place of care. JAMA: the journal of the American Medical Association. 2004; 291(1):88-93. [PubMed: 14709580]

12. Birch D, Draper J. A critical literature review exploring the challenges of delivering effective palliative care to older people with dementia. J Clin Nurs. 2008; 17(9):1144-1163. [PubMed: 18416791]

13. Sloane PD, Zimmerman S, Williams CS, Hanson LC. Dying with dementia in long-term care. Gerontologist. 2008; 48(6):741-751. [PubMed: 19139248]

14. Givens JL, Lopez RP, Mazor KM, Mitchell SL. Sources of stress for family members of nursing home residents with advanced dementia. Alzheimer Disease \& Associated Disorders. 2012; 26(3): 254-259. [PubMed: 22037596]

15. Engel SE, Kiely DK, Mitchell SL. Satisfaction with end-of-life care for nursing home residents with advanced dementia. J Am Geriatr Soc. 2006; 54(10):1567-1572. [PubMed: 17038076]

16. Givens JL, Kiely DK, Carey K, Mitchell SL. Healthcare proxies of nursing home residents with advanced dementia: Decisions they confront and their satisfaction with decision-making. $\mathrm{J}$ Am Geriatr Soc. 2009; 57(7):1149-1155. [PubMed: 19486200]

17. Elwyn G, O’Connor A, Stacey D, et al. Developing a quality criteria framework for patient decision aids: Online international delphi consensus process. BMJ. 2006; 333(7565):417. [PubMed: 16908462]

18. Stacey D, Bennett CL, Barry MJ, et al. Decision aids for people facing health treatment or screening decisions. Cochrane Database Syst Rev. 2011; 10:001431.

19. Whelan T, Levine M, Willan A, et al. Effect of a decision aid on knowledge and treatment decision making for breast cancer surgery: A randomized trial. JAMA. 2004; 292(4):435-441. [PubMed: 15280341]

20. Pignone M, Harris R, Kinsinger L. Videotape-based decision aid for colon cancer screening. A randomized, controlled trial. Ann Intern Med. 2000; 133(10):761-769. [PubMed: 11085838]

21. Kennedy AD, Sculpher MJ, Coulter A, et al. Effects of decision aids for menorrhagia on treatment choices, health outcomes, and costs: A randomized controlled trial. JAMA. 2002; 288(21):27012708. [PubMed: 12460093]

22. Green MJ, Peterson SK, Baker MW, et al. Effect of a computer-based decision aid on knowledge, perceptions, and intentions about genetic testing for breast cancer susceptibility: A randomized controlled trial. JAMA. 2004; 292(4):442-452. [PubMed: 15280342]

23. Molenaar S, Sprangers MA, Postma-Schuit FC, et al. Feasibility and effects of decision aids. Medical Decision Making. 2000; 20(1):112-127. [PubMed: 10638544]

24. Barry MJ. Health decision aids to facilitate shared decision making in office practice. Ann Intern Med. 2002; 136(2):127-135. [PubMed: 11790064] 
25. Frosch DL, Kaplan RM. Shared decision making in clinical medicine: Past research and future directions. Am J Prev Med. 1999; 17(4):285-294. [PubMed: 10606197]

26. Volandes AE, Paasche-Orlow MK, Barry MJ, et al. Video decision support tool for advance care planning in dementia: Randomised controlled trial. BMJ. 2009; 338:b2159. [PubMed: 19477893]

27. Hanson LC, Carey TS, Caprio AJ, et al. Improving Decision-Making for feeding options in advanced dementia: A randomized, controlled trial. J Am Geriatr Soc. 2011; 59(11):2009-2016. [PubMed: 22091750]

28. Kaldjian LC, Curtis AE, Shinkunas LA, Cannon KT. Review article: Goals of care toward the end of life: A structured literature review. American Journal of Hospice and Palliative Medicine. 2009; 25(6):501-511. [PubMed: 19106284]

29. Bogardus ST Jr, Tinetti ME. A taxonomy for goal setting in the care of persons with dementia. Journal of general internal medicine. 1998; 13(10):675-680. [PubMed: 9798814]

30. Gillick M, Berkman S, Cullen L. A patient-centered approach to advance medical planning in the nursing home. J Am Geriatr Soc. 1999; 47(2):227-230. [PubMed: 9988295]

31. Kaldjian LC, Shinkunas LA, Bern-Klug M, Schultz SK. Dementia, goals of care, and personhood: A study of surrogate decision makers' beliefs and values. American Journal of Hospice and Palliative Medicine. 2010; 27(6):387-397. [PubMed: 20167835]

32. Braddock CH III, Fihn SD, Levinson W, Pearlman RA. How doctors and patients discuss routine clinical decisions: Informed decision making in the outpatient setting. Journal of General Internal Medicine. 1997; 12(6):339-345. [PubMed: 9192250]

33. Curtis JR, White DB. Practical guidance for evidence-based ICU family conferences. Chest. 2008; 134(4):835-843. [PubMed: 18842916]

34. Engelberg R, Downey L, Curtis JR. Psychometric characteristics of a quality of communication questionnaire assessing communication about end-of-life care. J Palliat Med. 2006; 9(5):10861098. [PubMed: 17040146]

35. Stapleton RD, Engelberg RA, Wenrich MD, Goss CH, Curtis JR. Clinician statements and family satisfaction with family conferences in the intensive care unit*. Crit Care Med. 2006; 34(6):16791685. [PubMed: 16625131]

36. Mitnick S, Leffler C, Hood VL. American College of Physicians Ethics, Professionalism and Human Rights Committee. Family caregivers, patients and physicians: Ethical guidance to optimize relationships. Journal of General Internal Medicine. 2010; 25(3):255-260. [PubMed: 20063128]

37. Bercovitch R, Gillick M. Can goal-based advance planning guide medical care in the nursing home? Journal of the American Medical Directors Association. 2002; 3(5):287-290. [PubMed: 12807614]

38. Arcand M, Brazil K, Nakanishi M, Nakashima T, Alix M, Desson JF, Morello R, Belzile L, Beaulieu M, Hertogh CM, Toscani F, van der Steen JT. Educating families about end-of-life care in advanced dementia: acceptability of a Canadian booklet to nurses from Canada, France and Japan. Int J Palliat Nurs. 2013; 19:67-74. [PubMed: 23435535]

39. Volandes AE, Barry MJ, Chang Y, Paasche-Orlow MK. Improving decision making at the end of life with video images. Medical Decision Making. 2010; 30(1):29-34. [PubMed: 19675323]

40. Volandes AE, Brandeis GH, Davis AD, et al. A randomized controlled trial of a goals-of-care video for elderly patients admitted to skilled nursing facilities. J Palliat Med. 2012; 15(7):805-811. [PubMed: 22559905]

41. Volandes AE, Mitchell SL, Gillick MR, Chang Y, Paasche-Orlow MK. Using video images to improve the accuracy of surrogate decision-making: A randomized controlled trial. Journal of the American Medical Directors Association. 2009; 10(8):575-580. [PubMed: 19808156]

42. Weeks JC, Catalano PJ, Cronin A, et al. Patients' expectations about effects of chemotherapy for advanced cancer. N Engl J Med. 2012; 367(17):1616-1625. [PubMed: 23094723] 
What happens to people with dementia?

- Dementia cannot be cured.

- Dementia weakens the body, not just the mind.

- People with dementia may live for years, but get worse over time.

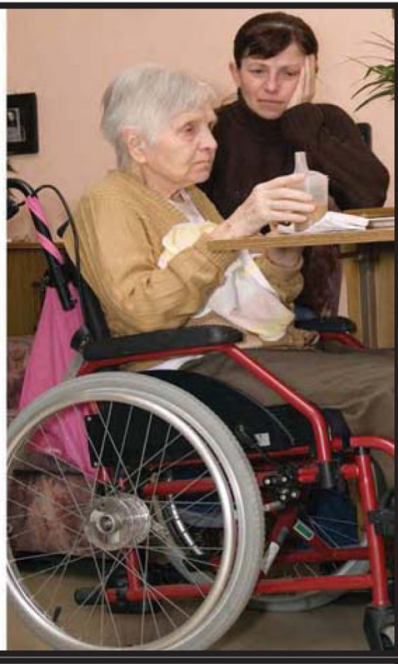

Goals of care: choosing a path

Prolonging

Life

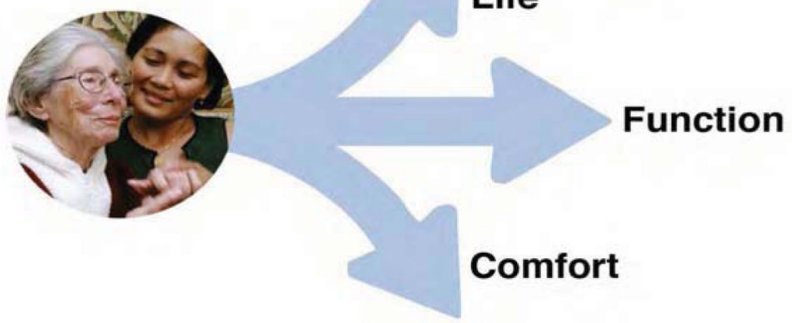

Figure 1.

Examples of Goals of Care Decision Aid Content 
Table 1

Characteristics of Research Subjects $(n=18)$

\begin{tabular}{|c|c|c|}
\hline \multirow[t]{2}{*}{ Subject Characteristics } & \multicolumn{2}{|c|}{ Baseline, $\mathrm{n}=18$} \\
\hline & Surrogate Decision Makers & Nursing Home Residents \\
\hline Age & Range: 40-85, Mean: 67 & Range: $69-102$, Mean: 90 \\
\hline \multicolumn{3}{|l|}{ Gender } \\
\hline Female & $10(56 \%)$ & $15(83 \%)$ \\
\hline \multicolumn{3}{|l|}{ Race/Ethnicity } \\
\hline White & $18(100 \%)$ & $18(100 \%)$ \\
\hline \multicolumn{3}{|l|}{ Religion } \\
\hline Protestant & $12(67 \%)$ & $12(67 \%)$ \\
\hline Catholic & $1(6 \%)$ & $1(6 \%)$ \\
\hline Jewish & $1(6 \%)$ & $1(6 \%)$ \\
\hline Other & $3(17 \%)$ & $4(22 \%)$ \\
\hline No Religion & $1(6 \%)$ & \\
\hline \multicolumn{3}{|l|}{ Educational level } \\
\hline High School & $1(6 \%)$ & \\
\hline Some college & $1(6 \%)$ & N/A \\
\hline College & $6(33 \%)$ & \\
\hline Advanced Degree & $10(56 \%)$ & \\
\hline \multicolumn{3}{|l|}{ Relationship to Resident } \\
\hline Spouse & $3(17 \%)$ & \\
\hline Daughter & $6(33 \%)$ & N/A \\
\hline Son & $6(33 \%)$ & \\
\hline Other Relative & $3(17 \%)$ & \\
\hline \multicolumn{3}{|l|}{ Global Deterioration Scale } \\
\hline Score $=5$ & & $8(44 \%)$ \\
\hline Score $=6$ & N/A & $3(17 \%)$ \\
\hline Score $=7$ & & $7(39 \%)$ \\
\hline \multicolumn{3}{|l|}{ Advance Directives } \\
\hline Do Not Resuscitate & & $14(78 \%)$ \\
\hline Do Not Hospitalize & & $4(22 \%)$ \\
\hline Do Not Tube Feed & N/A & $3(17 \%)$ \\
\hline MOST Form & & $4(22 \%)$ \\
\hline No Antibiotic Order & & $0(0 \%)$ \\
\hline Living Will or HCPOA/Guardian & & $7(39 \%)$ \\
\hline
\end{tabular}


Table 2

Fidelity to Decision Support Intervention

\begin{tabular}{|l|c|}
\hline Measure & Percentage \\
\hline 3-Month Follow-up Interview & $\mathrm{n}=18$ \\
\hline Surrogate viewed decision aid & $18(100 \%)$ \\
Surrogate present at care plan meeting & $16(89 \%)$ \\
GOC discussed & $12(67 \%)$ \\
Surrogate input on treatments & $14(78 \%)$ \\
Discussed personal goals & $8(44 \%)$ \\
Goal choice made at care plan & $11(61 \%)$ \\
Surrogate in agreement with goal & $11(61 \%)$ \\
\hline 3-Month Follow-up Chart Review & $\mathbf{n = 1 8}$ \\
\hline MD / NP / PA at meeting & $2(11 \%)$ \\
Documented discussion of GOC & $6(33 \%)$ \\
New treatment decisions & $7(39 \%)$ \\
New GOC in care plan & $3(17 \%)$ \\
\hline
\end{tabular}

GOC, Goals of Care; MD, Medical Doctor; NP, Nurse Practitioner; PA, Physician's Assistant 
Table 3

Quality of Communication and Decision-making on Goals of Care $(n=18)$

\begin{tabular}{|l|l|l|l|}
\hline Measure (scale) & Pre-Intervention & Post-Intervention & P value \\
\hline Knowledge (0-15) & 12.5 & 14.2 & $<0.001$ \\
\hline Quality of Communication (0-10) & $6.1(1.7)$ & $6.8(1.6)$ & 0.011 \\
\hline Surrogate-provider concordance on primary GOC & $50 \%$ & $78 \%$ & 0.003 \\
\hline Palliative Care Domain Score (0-10) & 1.8 & 4.3 & $<0.001$ \\
\hline
\end{tabular}

